INTERNATIONAL JOURNAL FOR

HISTORY, CULTURE AND MODERNITY

www.history-culture-modernity.org

Published by: Uopen Journals

Copyright: () The Author(s).

Content is licensed under a Creative Commons Attribution 4.0 International Licence

eISSN: 2213-0624

\title{
The Great Divergence Reconsidered: Or, Is it Time to Reconsider the Great Divergence Debate?
}

Joshua Allen Sooter

HCM 7: 1067-1079

DOI: $10.18352 / \mathrm{hcm} .598$

\section{Books reviewed}

Roman Studer, The Great Divergence Reconsidered: Europe, India, and the Rise to Global Economic Power (Cambridge, 20I5); Kaveh Yazdani, India, Modernity and the Great Divergence: Mysore and Gujarat (I7th to I9th C.) (Leiden, 20 I7); Prasannan Parthasarathi, Why Europe Grew Rich and Asia Did Not: Global Economic Divergence, I600-I800 (Cambridge, 20 I I).

\begin{abstract}
Twenty years ago, Kenneth Pomeranz's The Great Divergence (2000) reshaped debates over the historical causes of Europe's rapid nineteenthcentury industrialization and economic growth. By comparing the Yangzi Delta region of China to Britain, Pomeranz asserted that Europe was not exceptionally dynamic before the nineteenth century and that its divergence from Asia owed to colonial exploitation of the Americas and ecological contingencies, namely abundant coal deposits. Some recent studies have sought to refute or refine Pomeranz's thesis using the Indian subcontinent as an historical case study. This essay reviews three of these works and, in doing so, demonstrates current methodological limitations of this debate. Specifically, recent scholarship, although seeking to critique Pomeranz, employs his two-way comparative methodology, but in a manner that operates within a Eurocentric teleology and takes the European historical experience as normative.
\end{abstract}


Instead, I propose that scholars inquire after the historical connections among societies' plural-yet-connected historical trajectories.

Keywords: development, divergence, eurocentrism, modernity, Pomeranz

\section{Introduction ${ }^{1}$}

It has been nearly twenty years since Kenneth Pomeranz's The Great Divergence: China, Europe, and the Making of the Modern World (2000) asked the question 'Why Europe?' Pomeranz's book gave name to debates over the conditions and dynamics that account for Europe's rapid industrialization and economic growth in the nineteenth century. In brief, by comparing the Yangzi Delta region of China to Britain, Pomeranz argued that Europe was not exceptionally dynamic prior to the nineteenth century and that its divergence from comparable regions in Asia owed to external factors - colonial exploitation of the Americas - and ecological contingencies, namely abundant deposits of coal. Numerous scholars have sought to refine or refute Pomeranz's thesis, many using the historical example of the Indian subcontinent. Recent works point to the current methodological and archival limitations of the Great Divergence Debate, including a paucity of sources from South Asia. I examine several studies that utilize the historical experiences of the Indian subcontinent to counter Pomeranz's thesis even as they seek to recreate his two-way comparative methodology. Without new methodological approaches that move beyond binaristic comparative frameworks, some based on limited data, the meaningfulness of the historical conclusions and the intellectual-political stakes of the literature on this debate will diminish.

Pomeranz's Great Divergence argues that Europe did not enjoy socioeconomic or institutional advantages over other world centres prior to the nineteenth century. Rather, Europe 'diverged' from Asia only after c. I 800 CE. Pomeranz writes in dialogue with other 'California School' scholars, such as André Gunder Frank and R. Bin Wong, who also asserted that Europe's ascent to global power and industrial capitalism occurred due to historical contingency. These scholars' aims were revisionist against an older historiography maintaining that Europe's rise derived from distinct intellectual and cultural traits and dynamics 
that were internal to Europe. ${ }^{2}$ This revisionism was not without critics. For instance, David Landes' The Wealth and Poverty of Nations: Why Some are so Rich and Some so Poor (I998), published in the same year as Frank's ReOrient, contended, along Weberian lines, that Europe 'has been the prime mover of development and modernity' because of an (Protestant) entrepreneurial culture, the uniquely industrious nature of Europeans, a favourable climate, and so forth. ${ }^{3}$

Utilizing a two-way comparative model that examines both Asian and European economic paths as variations, Pomeranz does not assume the European historical experience to be normative nor does he assume the existence of a litany of self-evidently advantageous cultural traits. He constructs his comparative framework in light of two key insights. First, he distinguishes between the rapid industrialization of parts of Western Europe and the less dramatic and slower development of the whole of the European continent. Second, he utilizes analogous geographical regions as his units of analysis and comparison. Specifically, he compares Britain to China's Yangzi Delta region. He does so to avoid misleading or unhelpful comparisons between unalike macro regions. Pomeranz subsequently asserts that the socio-economic conditions that led to capitalist industrialization in Western Europe that other scholars have understood as being exclusive to Europe, such as long life expectancies, strong banking institutions, efficient corporations and tradefriendly state policies, were roughly coterminous in some of the most developed regions of Asia. His aim is 'to look for absences, accidents, and obstacles that diverted England from a path that might have made it more like the Yangzi Delta or Gujarat'. ${ }^{4}$

Pomeranz locates the factors for western Europe's nineteenth-century transformation as external to the continent. The procurement of foodstuffs from the colonial exploitation of the Americas, he claims, reduced the necessity of relegating European labour to sustainable subsistence agriculture. This decreased the need to maximize agricultural production on western European land, thereby diverting labour to non-subsistence related industries, a process also facilitated by the exploitation of rich fossil fuel deposits, specifically coal. The ensuing 'ecological breakthrough' stimulated industry and manufacturing, enabling Europeans' supremacy over global markets and eventual political and social hegemony. This argument frames Europe's divergence as an eighteenth and nineteenth-century departure from the developmental 
course shared by societies world-wide: 'we cannot understand preI 800 global conjunctures in terms of a Europe-centered world system; we have instead a polycentric world with no dominant center. Global conjunctures often worked to western Europe's advantage, but not necessarily because Europeans created or imposed them'. ${ }^{5}$ This contrasts with holding the European historical case as universal and normative; a measuring stick by which all other historical experiences fall short due to the 'lack' of some crucial economic-sociocultural-geographictechnological factors or determinants.

\section{Recent Revisions to the Great Divergence: Re-Centring Europe?}

Recently, some scholars have used the Indian subcontinent to challenge the narrative that Europe's divergence was relatively late and resulted from relative ecological and geographical happenstance. Two representative works are Roman Studer's The Great Divergence Reconsidered: Europe, India, and the Rise to Global Economic Power and Kaveh Yazdani's India, Modernity and the Great Divergence: Mysore and Gujarat (I7th to I9th C.). These contend that Europe's ascendance resulted from longstanding divergent trajectories and preceded the nineteenth century due, respectively, to market integration dynamics within the European continent and to sociocultural and scientific innovations. Both seek to refute aspects of Pomeranz's thesis using the historical case of India. Although their theoretical frameworks and causal explanations differ, both try to mirror Pomeranz's two-way comparison even as they refute central aspects of his argument.

Studer's The Great Divergence Reconsidered uses a methodology based in economics in an attempt to address the questions, 'Why was it Western Europe that led the economic development in the world and industrialised first? ... And why did it start in the late eighteenth century?' He begins by outlining the 'web' of overlapping and 'mutually influencing' factors that may have contributed to the 'rise of Europe' that economic historians and economists have identified. ${ }^{6}$ These include favourable geography; agricultural, social, scientific and technological factors; colonialism and imperialist ventures; as well as commercial activities and trade. The last of these constitutes Studer's raison d'être. 
His aim is to provide quantitative evidence that Europe featured superior internal 'market integration' in comparison to Asia and that this was a causal factor in the Great Divergence. Studer's goal is to 'improve' the 'empirical evidence' supporting the Smithian theory that market integration is key to economic development. To demonstrate this assertion, he attempts to show that Europe had significantly greater market integration than did the rest of the world and that this occurred internally to Europe prior to the nineteenth century. This directly conflicts with the thesis that regions of Asia, particularly portions of China and India, featured markets and commercial systems that were as sophisticated and efficient as those of Europe. ${ }^{7}$

Studer dedicates the first half of his book to showing that Europe already had a significant level of market integration prior to and during the eighteenth century. This was due to its geography, which was advantageous to the transport of commercial goods via water ways and a highly developed road network. The second portion of the book is a comparative study between Switzerland and the Western Ghats in the eighteenth century. His rationale for choosing the Western Ghats is solely based on geography (both 'micro' regions were mountainous, landlocked and had few navigable rivers, he states $^{8}$ ) and data availability, although it must be pointed out that he admits late in the book that sources for the Western Ghats are insufficient for valid data-driven statistical comparisons, casting further doubt on his choice of units for his 'comparative' study. Nevertheless, he states that the primary contemporaneous difference and historical later divergence between these regions resulted from Europe's much higher degree of market integration in the eighteenth century than India's.

Studer's methodology consists of quantitative analyses of grain prices in Europe and India -including relative price convergences within each region - to compare levels of market integration. His analyses show that Switzerland was more integrated into the European grain market than were comparable regions in the Indian subcontinent. The corresponding fate of Switzerland was increasing economic prosperity well into the nineteenth century, whereas 'fragmented markets and stagnation up to the middle of the nineteenth' characterized the Western Ghats. ${ }^{9}$ Yet, again, it is unclear how many conclusions Studer can draw from this 'comparison' because, as he himself states, there is little to no source data available for the Western Ghats. In fact, there is a shortage 
of sources from which financial and economic data preceding the nineteenth century in India, he informs the reader.$^{10}$ Nearly all of Studer's analyses, therefore, are of Switzerland vis-à-vis Europe because grain is the only commodity for which there is sufficient data to draw meaningful comparisons. ${ }^{\text {II }}$ Studer feels that this single-sourced dataset and the conclusions he draws from it, with little to no heed paid to the effects of colonialism or the coffee and tea plantation-based economy during the colonial era, constitute adequate evidence to claim that Europe's divergence occurred much earlier and was more gradual than Pomeranz and other California School scholars maintain.

Another work that seeks to reframe the explanation for the Great Divergence through an examination of qualities that made Europe unique and using India an example is Kaveh Yazdani's thoroughly researched and well-written India, Modernity and the Great Divergence: Mysore and Gujarat (I7th to Igth C.). Yazdani asks why 'advanced parts of Europe' transitioned from 'agrarian socio-economic formations with rudimentary capitalist elements to a predominantly industrial capitalist socio-economic system' (a condition he terms 'late modernity') whereas the pre-colonial Indian subcontinent did not. ${ }^{I 2}$ This occurrence is surprising, he maintains, despite the presence of thriving Indian commercial markets and the high living standards associated with capitalist industrial development. The societies in the Indian subcontinent, he posits, failed to move from 'middle modernity' to 'late modernity' due to sociocultural and institutional factors, not economic and geographic determinants. Yazdani produces a universal, unilinear and stadial schema of temporal-sociopolitical achievement (that is, gradations of 'modernity') by which other world cores are deemed lacking in comparison to Western Europe.

Yazdani follows Pomeranz's established approach of narrowing one's comparative parameters to analogous geographic-social units. He selects the post-Mughal states of Gujarat and Mysore. By choosing the two regions of the Indian subcontinent, Yazdani bases his comparisons on sources from small, exemplary regions of India. This is because the diversity of newly independent provinces in the eighteenth century make using the entirety of the Indian subcontinent as a unit of comparison impossible. He explicitly cites his debt to Pomeranz's use of the Yangzi River Delta to produce similar comparative parameters to Britain. 
Yazdani's chooses Gujarat and Mysore for two reasons: first because British colonial dominance was relatively delayed until the eighteenth century and second due to their respective socio-economic factors. Gujarat, he states, had a thriving economy and merchant community engaged in Indian Ocean-based trade that was relatively free from the reaches of the state. Mysore balances out the choice of Gujarat, according to Yazdani, because of its strong state-centralizing impulse and powerful military in the late eighteenth century. These factors, he states, led Mysore to pursue, "more than any other post-Mughal Indian province', ${ }^{13}$ the 'most serious attempts of economic, administrative and infrastructural semi-modernization.' ${ }^{14} \mathrm{He}$ compares Mysore and Gujarat to the economic, social, scientific, technological and political developments of Western Europe from the seventeenth to nineteenth centuries. He scrutinizes Mysore and Gujarat through an array of analytical categories, including agriculture, commercial activities, education standards, transportation, legal structures, the 'impact of caste and religion', and even 'the effects of colonialism' ${ }^{15} \mathrm{He}$ concludes that "parts of late I6th to late I8th century Mughal India and its successor states', including Gujarat and Mysore, 'were in a transitory phase where different modes of production coexisted with each other'. ${ }^{16}$

Yazdani constructs gradations of modernity using socioeconomic and cultural-intellectual conditions that coalesce into a rough temporal schema: early modernity (c. I000-I499 CE, and c. I200-I499 CE for Europe); middle modernity (c. I500-I $800 \mathrm{CE}$ ); and late modernity (c. I80o CE-present). The book's main contention is that, although the 'advanced' regions of 'middle modern' India were in some ways comparable to those of Western Europe, there were sociocultural traits and holdover modes of production within India that made post-Mughal states' transition to late modernity slow and uneven. Indeed, he argues that India did not fully achieve this transition until the middle of the twentieth century. Europe is thus the implicit standard of modernity due to its 'undisputed preponderance during the I 9 th century' and because Yazdani uses the articulations of the 'modernity it presented' as the ultimate criteria of comparison. ${ }^{17}$

The stadial schema through which Yazdani makes his comparisons highlights a central point of contention between his and Pomeranz's accounts. Yazdani states that he does not want to assume industrialization 
as a predetermined historical result for any given historical trajectory, arguing for the necessity of studying long-term structural causal mechanisms that explain Europe's divergence. Pomeranz is committed to emphasizing socio-economic parity between Europe and Asia until the nineteenth century and views this as critical to avoiding a deterministic and teleological historical account. A footnote in Yazdani's Introduction is indicative of the disagreement:

Pomeranz's argument is more speculative than historical, as he overestimates fortuitous conjunctures at the expense of long-term causations in explaining the Industrial Revolution and the Igth century bifurcation between East and West. Long- and short-run internal and external conjunctures that were causally determined such as the historical accumulation of knowledge and techno-scientific development, the creative decisions and practices of individuals and groups, as well as institutional and political settings seem to have been at least as important as contingent dynamics. ${ }^{18}$

Yazdani views his stadial schema, which historians might interpret as implying teleology rather than serving as mere descriptive categories, as necessary if his work is to extend beyond a short-term study of contingency. This reasoning seemingly stems from his stated influence by the Annales School and its focus on the longue durée.

Yazdani concedes that Pomeranz's thesis that 'land-saving products' from the New world 'such as cheap guano, cotton, sugar, wood, etc. relieved Europe's 'eco-system' and stimulated further specialization in manufactures' has merit. ${ }^{19} \mathrm{He}$ asserts, however, that Europe possessed advantages prior to the early nineteenth century that negate this fact. Although there were structural similarities among Europe, China, India and the Ottoman Empire during middle modernity, including agricultural productivity, long-distance commerce, increasing state centralization and cultures of learning, Europe was more dynamic during this period and transitioned into late modernity because of intellectual and sociopolitical innovations that began much earlier.

For instance, when arguing that Mysore was in a transitional phase to semi-modernization and could have had an industrial breakthrough in the absences of colonial rule, he states that that this would have been 'later, when the socio-economic circumstances would have been ripe 
for such a transition'. This constitutes a developmentalist schema in which, although there are multiple paths to 'late modernity', the standard road markers, waypoints and the end goals of modernity are decidedly European conditions. The book operates within a framework and language of 'lack' or temporal backwardness when describing Indian technological capabilities, and scientific achievements or political cultures: 'Mysore seriously lagged behind Europe when it came to theoretical sciences, literacy, the circulation of knowledge and institutions of higher learning'. This is the overdetermined conclusion when scholars use Europe's historical experiences as the measures of modernity. It results in historical causation being assigned based on normative value judgements, such as when 'human rights or democratic and secular values' become the criteria for 'being modern', a standard from which Mysore in the eighteenth century, the reader is told, 'was far away'. ${ }^{20}$ For its part, Gujarat lacked an 'industrious' or 'consumer' revolution, had a smaller 'middle class' and therefore 'groundbreaking inventions and innovations in production were less probable in Gujarat' ${ }^{21}$ Yazdani admits this and claims to skirt a 'gray' zone between 'Eurocentric' explanations of Europe's divergence that proclaim Europe's special characteristics and dynamism and impeding internal restraints within India with California School studies that, to him, overemphasize similarities between pre-divergence Europe and Asia.

Both Studer and Yazdani use a comparative methodology similar to Pomeranz's but to ends that re-instate narratives of European difference. This is because bringing a comparative lens to the question 'why Europe?' necessitates conclusions that emphasize the uniqueness of Europe. A two-way comparative model works best in the absence of assumptions of pre-existing difference between the units of analysis (e.g. Asia and Europe) and cannot work when scholars utilize one of the unit's (e.g. Europe) features as the grounds of comparison. Pomeranz himself can claim to escape a Eurocentric perspective only because he emphasizes contingency as resulting in Europe's industrialization and global political dominance. As this mode of debate continues and the scope and novelty of future studies' interventions become increasingly narrow, each new work runs the risk of telling readers more about the assumptions and politics comprising the terms of comparison instead of offering convincing historical answers. 


\section{(Plural) Paths Forward in the Great Divergence Debate}

Pomeranz's attempt to avoid European exceptionalism as both historical narrative and as a causal explanation finds sympathetic criticism in Prasannan Parthasarathi's Why Europe Grew Rich and Asia Did Not: Global Economic Divergence, I600-I80o (20I I). This work uses the case of India to argue, akin to Pomeranz and counter to Studer and Yazdani, that economically developed regions in India and Europe in the seventeenth century and lasting until the late eighteenth century were more similar than different. Instead of searching for factors that made Europe unique from Asia, Parthasarathi points to the 'profound similarities in political and economic institutions' between the 'advanced' areas of Asia and Europe. This statement betrays his debt to Pomeranz, particularly the direct comparison of specific, equivalent Indian (i.e. North and South India, Bengal and Gujarat) and European (i.e. Britain) regions to highlight their commonalities, as well as his departure. Following Joseph Stiglitz's arguments that there is no 'straightforward correspondence between economic variables and economic outcomes' and scholarship pointing to the role that economic situation and context influences outcome in agents' choices, he contends that divergent development trajectories do not necessarily stem from radically differing 'economic institutions' and factors. Thus, for him, context and contingency are the loci of study. Parthasarathi's separation of historical variables from outcomes enables him to move beyond the question of why the West developed and the rest did not, which he views as binaristic and intellectually limiting. Whereas Pomeranz frames Europe's divergence as an aberration, Parthasarathi asserts that there were 'plural paths of change'. ${ }^{22}$

Considering this theoretical and methodological intervention in the Great Divergence Debate, Parthasarathi turns to identifying the historical pressures that generated Britain's path. He argues that there were two primary factors that generated Britain's divergence. The first was the British desire to challenge Indian global dominance in the production of cotton textiles. Indian textiles, which he argues were in the eighteenth century the most 'manufactured good in world trade', ${ }^{23}$ held an overwhelming market-share advantage due to their price and array of options in type and quality. This propelled British technological innovation. The second pressure was the shortage of wood in Britain, which necessitated the use of coal for fuel. This contingency created the 
opportunity for the invention of the steam engine, a breakthrough with tremendous consequences for efficient light and heavy industry and transportation. Here Parthasarathi mirrors Pomeranz's identification of Britain's abundant coal deposits as a principal cause of its divergence.

Parthasarathi emphasizes that these innovations comprised context-dependent solutions to problems that did not exist on India subcontinent. Although he notes that these ecological problems existed in China's highly developed Yangzi River Valley, he asserts that the challenges the Chinese faced were more 'radical' than ecological ones alone, and technological breakthroughs alone were insufficient to meet Chinese needs. Thus, his is ultimately a technological and ecological argument. Parthasarathi contrasts his explanations of Europe's divergence with those emanating from classic scholarly literature in the vein of Adam Smith that ascribe Europe's divergence and industrialization to factors such as private property rights, laissez faire economics and lower populations, or studies that lionize scientism and European traditions of thought. ${ }^{24}$

Parthasarathi's notion of 'plural paths' contrasts with Yazdani's stadial schema and enables the study of contingency, specifically in the form of pressures and opportunity, in relation to long-term structures, rather than opposing them. This better enables scholars to produce syntheses of difference and similarity regarding historical experience than does a binaristic comparative methodology. Why Europe Grew Rich and Asia Did Not additionally takes the role of global interconnectedness and exchange (consensual and forced) seriously. For Parthasarathi, regardless of the structures and longue durée factors in Britain's divergence, intercourse with India was a critical factor in industrialization.

The debate over what caused the Great Divergence should move beyond framing large world regions as discrete and largely isolated units of comparison. Even prior to the Great Divergence and industrialization interconnectedness and exchange characterized the world, the nature and extent of which transformed radically after the onset of industrial capitalism and European political hegemony. Binaristic comparative studies cannot sufficiently untangle this history of exchange and interrelation. If scholars cannot construct studies attuned to this historical connectedness and the conjunctures that it produced, in addition to conditional contingencies and long-standing dynamics and structures, then in the absence of new, relevant archives perhaps it is time for a new question. Rather 
than asking 'Why Europe?', perhaps they should inquire after the links among societies' plural-yet-connected historical trajectories.

\section{Notes}

I The author would particularly like to thank Gaurav Garg of New York University for his comments and suggestions on this review essay.

2 See André Gunder Frank, ReOrient. The Global Economy in the Asian Age (Berkeley, I998). Frank has two main objectives: the first is to 'pull the rug out' from underneath Eurocentric historiography, and the second is to cast doubt on the assertion (made first by Marx, then Weber and later by scholars such as Immanuel Wallerstein) that the modern world system, and Europe's dominance, originated around c.I500 CE (xv). He subsequently argues that Asia was the primary participant in the world economy until the nineteenth century and that its primacy had characterized the world system for over a millennium prior. See also R. Bin Wong's China Transformed: Historical Change and the Limits of European Experience (Ithaca, I997). Wong evaluates Chinese and European economic, social and national development in 'terms of each other' (I43). Rather than explaining China's historical socioeconomic development by comparing it to European 'successes', he applies the same measures of inquiry (e.g. evidence of proto-capitalism) to both Europe and China. This results in a comparative history that resists explaining China's historical trajectory in negative terms.

3 David Landes, The Wealth and Poverty of Nations: Why Some are so Rich and Some so Poor (New York, I998), xx-xxi. Landes and Frank famously held a debate on their divergent views at the Northeastern University World History Center in December 1998.

4 Kenneth Pomeranz, The Great Divergence: China, Europe, and the Making of the Modern World (Princeton, 2000), 8.

5 Pomeranz, The Great Divergence, 4.

6 Roman Studer, The Great Divergence Reconsidered: Europe, India, and the Rise to Global Economic Power (Cambridge, 2015), 3.

7 Studer, The Great Divergence Reconsidered, I79.

8 To the author of this article, that both regions are mountainous and landlocked seems to be the extent of their similarity. Rainforest covers much of the Western Ghats due to high rainfalls from the monsoon winds 
encountering the mountains. The region corresponding to the modern state of Switzerland is a less densely wooded temperate zone with pasture.

9 Studer, The Great Divergence Reconsidered, I80.

Io Ibid., 20.

I I Ibid., 3I.

I2 Kaveh Yazdani, India, Modernity and the Great Divergence: Mysore and Gujarat (I7th to I9th C.) (Leiden, 2017), 6.

I3 Ibid., 9.

I4 Ibid., Io.

I5 Ibid., 3 .

I6 Ibid., 20.

I7 Ibid., 2.

I 8 Ibid., 64 .

I9 Ibid., 57.

20 Ibid., 352-3.

2 I Ibid., 554.

22 Prasannan Parthasarathi, Why Europe Grew Rich and Asia Did Not: Global Economic Divergence, I600-I800 (Cambridge, 201 I), 2.

23 Ibid., 2.

24 Parthasarathi cites Margaret C. Jacob's Scientific Culture and the Making of the Industrial West (Oxford, I997) and Joel Mokyr's The Gifts of Athena: Historical Origins of the Knowledge Economy (Princeton, 2002) as examples of this line of argumentation.

\section{About the Author}

Joshua Allen Sooter is a Ph.D. candidate in the history department of New York University (NYU) specializing in global and East Asian history, specifically the history of ideas and empires. Prior to NYU, he completed an M.A. at Northeastern University and lived and studied in Taiwan and mainland China. Joshua's research focuses on concept formation, international law, cross-cultural translations of ideas and intellectual paradigms, and religious interactions. Having grown up on a farm and subsequently lived on multiple continents, he is interested in how ideas move across time and space and how 'common senses' shift. His dissertation is on the construction of the concepts of religion and the secular in China from the I850s to I890s. E-mail: joshuasooter1@gmail.com 